\title{
End-of-life medical decisions in France: a death certificate follow-up survey 5 years after the 2005 act of parliament on patients' rights and end of life
}

Sophie Pennec ${ }^{1,2^{*}}$, Alain Monnier ${ }^{1}$, Silvia Pontone $e^{1,3}$ and Régis Aubry ${ }^{4,5}$

\begin{abstract}
Background: The "Patients' Rights and End of Life Care" Act came into force in France in 2005. It allows withholding/withdrawal of life-support treatment, and intensified use of medications that may hasten death through a double effect, as long as hastening death is not the purpose of the decision. It also specifies the requirements of the decision-making process. This study assesses the situation by examining the frequency of end-of-life decisions by patients' and physicians' characteristics, and describes the decision-making processes.

Methods: We conducted a nationwide retrospective study of a random sample of adult patients who died in December 2009. Questionnaires were mailed to the physicians who certified/attended these deaths. Cases were weighted to adjust for response rate bias. Bivariate analyses and logistic regressions were performed for each decision.

Results: Of all deaths, 16.9\% were sudden deaths with no information about end of life, 12.2\% followed a decision to do everything possible to prolong life, and $47.7 \%$ followed at least one medical decision that may certainly or probably hasten death: withholding (14.6\%) or withdrawal (4.2\%) of treatments, intensified use of opioids and/or benzodiazepines (28.1\%), use of medications to deliberately hasten death (i.e. not legally authorized) $(0.8 \%)$, at the patient's request $(0.2 \%)$ or not (0.6\%). All other variables held constant, cause of death, patient's age, doctor's age and specialty, and place of death, influenced the frequencies of decisions. When a decision was made, $20 \%$ of the persons concerned were considered to be competent. The decision was discussed with the patient if competent in $40 \%$ (everything done) to $86 \%$ (intensification of alleviation of symptoms) of cases. Legal requirements regarding decision-making for incompetent patients were frequently not complied with.
\end{abstract}

Conclusions: This study shows that end-of-life medical decisions are common in France. Most are in compliance with the 2005 law (similar to some other European countries). Nonetheless, the study revealed cases where not all legal obligations were met or where the decision was totally illegal. There is still a lot to be done through medical education and population awareness-raising to ensure that the decision-making process is compatible with current legislation, the physician's duty of care and the patient's rights.

\footnotetext{
* Correspondence: pennec@ined.fr

${ }^{1}$ Institut National d'Etudes Démographiques, 133, boulevard Davout, 75980

Paris cedex 20, France

${ }^{2}$ Australian Demographic and Social Research Institute, Australian National

University, Canberra, Australia

Full list of author information is available at the end of the article
} 


\section{Background}

The annual number of deaths in France, ranging between 500,000 and 600,000, has varied relatively little since World War II, with the decline in mortality rates being offset by population growth. However, as the large postwar cohorts grow older, the numbers of deaths will increase considerably (to 770,000 by 2050). Whereas just after World War II most people died at home, in France, as in other developed countries, most now die in hospital.

These changes are bound to affect the way death is seen and experienced, and to influence future health policy and medical practices. As medical progress increasingly prolongs the life expectancy of the chronically ill, endof-life questions such as place of death, palliative care, decisions to withdraw or reduce active treatment, staff resources, the role of the family in end-of-life care and demand for euthanasia are becoming ever more critical.

End-of-life legal provisions vary widely across Europe. In France, the Act of 22 April 2005 on Patients' Rights and End-of-Life Care [1] introduced three main measures: Firstly, it prohibits "unreasonable obstinacy" and therefore the continuation of futile medical treatments. Secondly, it strengthens the right of access to palliative care for any person whose condition requires such care, and recognizes that, under certain conditions, pain and symptom relief may require drugs that, at high doses, may have the unintended effect of shortening the patient's life. Thirdly, it strengthens the principle of patient autonomy and of discussion with the patient. If the patient is not competent, the end-of-life medical decision must be taken after discussion with a trusted third party or surrogate (if the patient has named one), and the family, if any, and after consultation with medical staff or colleagues.

Nevertheless, legalising euthanasia remains a highly controversial topic in the public and political arena, as seen during the 2012 presidential election.

In Europe, various surveys [2-5] have shown that in order to better understand end-of-life conditions, it is important to study the medical decisions taken prior to death. In France, the only surveys on end-of-life decisions conducted until now focused on deaths in hospital or emergency wards [6-9]. The survey Fin de Vie en France ("End of life in France"), conducted in 2010, concerned all deaths, regardless of cause or place (hospital, home, nursing home...). It provides an overview of endof-life care in France that can be used as a baseline for assessing future developments.

This paper focuses on the medical decisions relating to end-of-life care in France. It looks at how the decisions varied according to the person's and physician's characteristics. It also investigates the extent to which these decisions comply with the 2005 law.

\section{Methods}

Retrospective survey of physicians

As in previous European surveys [10], we conducted a retrospective survey on a sample of deaths where the respondents were the certifying physicians.

This sample of 14,999 deaths was selected by InsermCepiDc (Centre d'épidémiologie sur les causes médicales de décès) using a systematic random procedure. We ensured that it was representative (in terms of age, sex, place of death and region of death) of the 47,872 persons aged 18 and over who died in France in December 2009. Stratification by cause of death (a proxy for the likelihood of an end-of-life decision) was not possible because of the delay in registration of causes of death.

For each death, we identified the certifying physicians on the death certificates and we mailed them the questionnaire with instructions for replying. Physicians could respond either by post (with paid-reply envelope) or online. These two response channels involved trusted third parties (virtual for Internet responses) to ensure medical confidentiality with regard to the deceased and the anonymity of both the deceased persons and the physicians taking part in the study [11]. Three follow-up letters were sent and a follow-up phone call was made.

We also conducted a telephone survey on a sample of 620 non-responding physicians to ensure that the results were representative. We recorded their socio-demographic profiles and their reasons for non-response.

\section{Questions and variables}

The questionnaire was based on the Eureld survey questionnaire [10] but was adapted to take account of the French legal context and of the results of preliminary tests. It comprised 113 questions (see Additional file 1). End-of-life medical decisions and the decision-making process were explored in the middle part of the questionnaire after questions about the end-of-life context (characteristics of the deceased person, physician, place of death, whether palliative care had been provided). Another section comprised questions on the physician's feelings about the death. The last section asked the physicians whether they habitually respond to surveys and what made them decide to respond to this particular survey if such was the case.

The key questions about end-of-life medical decisions were (see Additional file 2) (1) whether first of all everything was done to prolong the patient's life (2) whether a treatment of any kind was withheld; (3) whether a treatment of any kind was withdrawn; (4) whether a treatment to alleviate the symptoms was intensified (opioids, benzodiazepines and/or any other treatment) and (5) whether a medication was administered to the patient to deliberately end his/her life. For questions (2) to (4), three subquestions investigated the physician's intention: (a) did 
he/she know that his/her decisions could hasten the death (b) did he/she take the decision with the explicit intention of hastening the death and (c) did he/she consider the decision to have hastened the death. We classified the answers to these questions to ensure maximum similarity with the EURELD classification of medical end-of-life decisions (as published in Van den Heide [4]): when one of questions (2) (3) and one of their sub-questions (a) (b) were answered yes, the case was classified as "non treatment decision"; when question (4) and one of its sub-questions (a) (b) were answered yes, the case was classified as "intensification of alleviation of symptoms with possible life shortening effect"; when question (5) was answered yes, we classified the case as "using a medication to deliberately hasten death", differentiating between treatment at the patient's explicit request, administration by the patient him/herself in "physician-assisted suicide" or administration by a nurse or a physician. When questions (2) to (5) were answered no and question (1) was answered yes, the case was classified as "life-prolonging decision"; when questions (1) and (5) were answered no and the sub-questions (a) or (b) to questions (2) (3) (4) were answered no, we classified the case as "no decision". When questions (2), (3) or (4) were answered "yes" and sub-questions (a) and (b) were answered "no" or "missing", the case was classified as "medical decision without any intention regarding death".

When more than one question (1) to (5) had been answered yes, the decision with the most explicit intention took precedence over other decisions. In cases of similar intention, question (5) took precedence over question (4), which took precedence over question (3), which took precedence over question (2).

We define as sudden deaths those deaths that the physician considered as sudden and unexpected and for which he/she cannot give any information about the end of life. Some deaths were qualified as sudden by the physician, although he/she was able to give information about end-of-life decisions, and such a decision did exist in $60 \%$ of those cases. We therefore included them in our study of "non sudden deaths".

Information on the person's ability to express his/her wishes was based on what the physician had noted from his/her discussion of the decision with the person, and on the reasons put forward for not having had such a discussion. Some persons were judged not competent to be involved in a discussion about their wishes, and some further persons, after taking part in such a discussion, were judged not competent to appreciate their situation and/or to decide for themselves. We did not have any clear information about the persons' abilities in other cases. We considered that the remaining persons were competent.

\section{Participation}

Among the entire initial sample of 14,999 deaths, 646 of the certifying physicians could not be identified. No physician was asked about more than four deaths, even if they had certified more. In all, 14,080 questionnaires were sent to 11,828 certifying physicians (of whom $14 \%$ had signed more than one death certificate). 461 questionnaires did not reach the addressee owing to postal problems or typing errors; 608 responses did not include a completed questionnaire (e.g., physician no longer practising or not the attending physician). 5,217 completed questionnaires were received, giving an overall participation rate of $40 \%$ [12]. Only a quarter of responses were obtained online even though respondents were given a full guarantee of anonymity with both collection modes. The results presented are based on 4,891 questionnaires since 327 concerned deaths outside the observation period.

\section{Quality control and weighting}

The characteristics of the 4,891 deaths in the survey are very close to those of all deaths in December 2009. There is a slightly higher percentage of deaths in public hospitals (55\% versus 50\%) and a correspondingly lower percentage at home, in private hospitals and retirement homes. Cancers and infectious diseases are slightly overrepresented, and cardio-vascular diseases and deaths from external causes are under-represented.

The answers were weighted for non-response bias according to the number and distribution of the reference variables used to select the initial sample of death certificates: age and sex of the deceased, place of death and region of residence.

\section{Statistical analysis}

The categorical data were described using frequencies and percentages. Univariate and bivariate analyses were tested with the exact Fisher test instead of a standard Chi square because of the low numbers in some categories. It tests the relation between a variable and a particular medical decision, i.e. whether the observed distribution of a variable for a particular medical decision is different from cases without this medical decision. Logistic regressions were performed for each medical decision with more than 150 observed cases, taking into account both patients' and physicians' characteristics. All tests were performed at a significance level of $1 \%$. Logistic regressions (not shown) were performed to determine the variables or characteristics that remain significant, all other variables held constant. The results section focuses on the significant effects of these variables. The statistical analyses were performed using the SAS Version 9.2 statistical software package. 
Ethics

This survey was approved by the Comité Consultatif sur le Traitement de l'Information en Matière de Recherche dans le Domaine de la Santé (CCTIRS) in January 2010 and authorized by the Commission Nationale de l'Informatique et des Libertés data protection committee (CNIL, - authorization No. 1410166 at sitting 2010-107 of 15 April 2010).

\section{Results}

\section{End-of-life medical decisions}

We had to exclude 168 cases owing to missing data. Sudden deaths $(n=798)$ amounted to $16.9 \%$ of the total (Table 1). For 2,252 non-sudden deaths, one or more decisions were made that possibly or certainly hastened death. For almost half of these deaths, there were two or more decisions. In $34 \%$ of all deaths, a life-prolonging treatment was withheld; in $11 \%$ it was withdrawn. In $29 \%$ of cases alleviation of pain and/symptoms was intensified and in $0.8 \%$ a medication was administered deliberately to hasten death.

Considering only the most important decision for each death, the proportion of cases with administration of medication to deliberately hasten death does not change ( $0.8 \%$ of all deaths). Of these 38 decisions, 11 were at the patient's request.

The physician reported increasing opioid and/or benzodiazepine doses in another $28 \%$ of all deaths. Withdrawal of life-prolonging treatment was decided in $4 \%$ of all deaths, and life-prolonging treatment was

Table 1 Frequency of all the different end-of-life medical decisions

\begin{tabular}{|c|c|c|c|c|c|c|c|}
\hline & \multirow{2}{*}{\multicolumn{3}{|c|}{$\begin{array}{c}\text { All decisions } \\
\text { Weighted data }\end{array}$}} & \multirow[b]{3}{*}{$\begin{array}{l}\text { Unweighted } \\
\text { data } \mathrm{N}\end{array}$} & \multirow{2}{*}{\multicolumn{3}{|c|}{$\begin{array}{c}\text { Most important decision } \\
\text { Weighted data }\end{array}$}} \\
\hline & & & & & & & \\
\hline & $\mathbf{N}$ & Percentage & $\begin{array}{l}\text { 95\% Confidence } \\
\text { interval }\end{array}$ & & $\mathbf{N}$ & Percentage & $\begin{array}{l}\text { 95\% Confidence } \\
\text { interval }\end{array}$ \\
\hline Sudden death & 798 & 16.9 & $15.8-18.0$ & 789 & 798 & 16.9 & $15.8-18.0$ \\
\hline \multicolumn{8}{|c|}{ Medical decision without any intention regarding death } \\
\hline Life-prolonging treatment & 1513 & 32 & $30.7-33.4$ & 588 & 576 & 12.2 & 11.3.13.2 \\
\hline Treatment withheld & 325 & 6.9 & $6.2-7.6$ & 140 & 140 & 3 & $2.5-3.5$ \\
\hline Treatment withdrawn & 86 & 1.8 & $1.4-2.2$ & 15 & 15 & 0.3 & $0.2-0.5$ \\
\hline $\begin{array}{l}\text { Intensification of treatment to alleviate symptoms } \\
\text { with opioids or benzodiazepines }\end{array}$ & 386 & 8.2 & $7.4-8.9$ & 252 & 246 & 5.2 & $4.6-5.8$ \\
\hline $\begin{array}{l}\text { Intention of treatment to alleviate symptoms with } \\
\text { medications other than opioids or benzodiazepines }\end{array}$ & 199 & 4.2 & $3.6-4.8$ & 97 & 97 & 2.1 & $1.7-2.5$ \\
\hline None of the above & 599 & 12.7 & $11.7-13.7$ & 571 & 599 & 12.7 & $11.7-13.7$ \\
\hline $\begin{array}{l}\text { Medical end-of-life practice that possibly } \\
\text { or certainly hastened death }\end{array}$ & & & & 2239 & 2252 & 47.7 & \\
\hline Treatment withheld & 1594 & 33.7 & & 691 & 688 & 14.6 & $13.6-15.6$ \\
\hline Knowing that the decision may hasten the death & 1526 & 32.3 & $31.0-33.6$ & 657 & 655 & 13.9 & $12.9-14.9$ \\
\hline With the intention of hastening death & 68 & 1.4 & $1.1-1.8$ & 34 & 33 & 0.7 & $0.5-0.9$ \\
\hline Treatment withdrawn & 531 & 11.2 & & 202 & 199 & 4.2 & $3.6-4.8$ \\
\hline Knowing that the decision may hasten the death & 465 & 9.8 & $9.0-10.7$ & 162 & 161 & 3.4 & $2.9-3.9$ \\
\hline With the intention of hastening death & 66 & 1.4 & $1.1-1.7$ & 40 & 38 & 0.8 & $0.6-1.1$ \\
\hline $\begin{array}{l}\text { Intensification of treatment to alleviate pain } \\
\text { and/or symptoms (opioids/benzodiazepines) }\end{array}$ & 1381 & 29.2 & & 1346 & 1327 & 28.1 & $26.8-29.4$ \\
\hline Knowing that the decision may hasten the death & 1324 & 29.0 & $26.7-29.3$ & 1306 & 1288 & 27.3 & $26.0-28.5$ \\
\hline With the intention of hastening death & 57 & 1.2 & $0.9-1.5$ & 40 & 39 & 0.8 & $0.6-1.1$ \\
\hline Use of a drug to deliberately end life* & 38 & 0.8 & $0.5-1.1$ & 38 & 38 & 0.8 & $0.5-1.1$ \\
\hline At patient's request & 11 & 0.2 & $0.1-0.4$ & 10 & 11 & 0.2 & $0.1-0.4$ \\
\hline
\end{tabular}

Sudden deaths: deaths declared "sudden and unexpected" and on which the physician has no information about the end of life.

The weighted percentages are weighted for non-response bias.

All decisions = every affirmative answer to questions about medical decisions.

Most important decision = when more than one decision is observed, the one with the most explicit intention (or awareness) of hastening death

(see classification details in Methods).

* no doctor assisted suicide have been observed.

Missing values: 168. 
withheld in another 15\% of all cases. These medical decisions were made with the explicit intention to hasten death in $0.8 \%, 0.8 \%, 0.7 \%$ of cases, respectively.

In all, considering only the most important medical decisions, $3.1 \%$ of all deaths followed a decision to hasten death.

For $12.2 \%$ of all deaths, the sole reported medical decision was doing everything possible to prolong life, and for $12.7 \%$ no decision was made (no decision to do everything to prolong life and none of the other decisions mentioned in the questionnaire). In $11 \%$ of cases a medical decision without any intention regarding death was reported.

\section{End-of-life medical decisions by patient's and physician's characteristics}

The pathology (cause of death and incurability) and age of the deceased were decisive in end-of-life decisions. The frequency of end-of-life decisions varies from $71 \%$ for cancer to $41 \%$ for cardio-vascular diseases. For cancer patients, 3 in 4 end-of-life medical decisions consisted of intensifying alleviation of symptoms; for respiratory diseases, end of life decisions were more diverse, with intensification of alleviation of symptoms in $40 \%$ of cases and withholding a treatment in 50\%. It is difficult to interpret the variations in administration of a drug to deliberately end life owing to the small numbers concerned (Table 2).

The medical decision to withhold a treatment increases steadily with age from $9.4 \%$ with the youngest patients to $22 \%$ with the oldest. Conversely, implementation of lifeprolonging treatments declines with age, from $24.8 \%$ to $11.3 \%$. For patients aged over 50 , intensification of alleviation of symptoms varies little with age.

The frequencies of the different decisions by respondent physicians' characteristics are shown in Table 3. The patient's pathology and the number of deaths certified in the previous three months were directly linked to physician's speciality: $46 \%$ of cancer specialists certified more than 10 deaths in the previous three months compared with $10 \%$ of general practitioners, cardiologists and surgeons. Logistic regressions (detailed results not shown) confirm and clarify the decisive influence of the patient's pathology on the end-of-life decisions made. All other variables held constant, physicians involved in the care of cancer patients reported significantly less often that they had "done everything possible to prolong life". They more often withheld treatment than those treating other pathologies (except cardio-vascular and digestive diseases), and more often intensified the alleviation of symptoms. The age of the patient does not seem to be a determinant for the type of end-of-life decision (nontreatment decisions or intensifying the alleviation of symptoms). However, the older the patients, the less frequent the decision to do everything possible to prolong life. Lastly, there is little differentiation by physician's speciality, except for anaesthesiologists and intensivists and emergency physicians, who were more likely to do everything possible to prolong life, and cancer specialists who were more likely to intensify the alleviation of symptoms. Young physicians seem to be less likely to do everything possible to prolong life and are more likely to intensify the alleviation of symptoms. End-of-life decisions are more likely to be made in hospital than at home.

\section{Characteristics of the decision-making process}

We have exploitable information about how and why the decision was made only for cases where the end-of-life decision and life-prolonging treatment matches the last affirmative answer to questions (1) to (5), i.e. in $91 \%$ of cases.

When such a decision was made, 1,706 persons were judged not competent (66\% of all decisions) and in $13 \%$ of case we had no information about the persons' competence. We considered that the remaining 545 persons were competent. (21\%)

In $70 \%$ of the cases, when an end-of-life decision was made, the persons, when competent, were involved in the discussion. The greater the likelihood that the decision made by the physician would hasten death, the more frequently he/she discussed it with the patient, if competent (see Table 4).

According to the responding physicians, when an endof-life decision or an explicit life-prolonging decision was made, $16 \%$ of persons had expressed at some point a wish to hasten death, although only $1.7 \%$ had explicitly requested euthanasia. The decision was made at the patient's explicit request in almost $15 \%$ of cases. The greater the likelihood that the decision would hasten death, the higher the percentage of persons who had expressed a wish to hasten death (from $8 \%$ for those with a treatment withheld to $38 \%$ for those with a medication given to deliberately hasten death) or who requested euthanasia ( 0.5 to $17 \%$ ).

When an end of life decision or an explicit lifeprolonging decision was made and when the patient was incompetent, $1.5 \%$ of the persons had expressed their wishes through written advance directives. For the responding physicians, these advance directives were an important part of the decision in $72 \%$ of cases. $50 \%$ of patients had appointed a trusted third party, who took part in discussions about decisions to be made at later stages of the disease in $90 \%$ of cases. The decisions were discussed in $45 \%$ of cases with colleagues and in $31 \%$ of cases with nursing staff members. No such discussion (either with colleagues and/or nursing staff, and/or described as a part of a "collective" process) was reported 
Table 2 Frequency of all the different medical end-of-life decisions in France by patients' characteristics (non-sudden deaths)

\begin{tabular}{|c|c|c|c|c|c|c|c|c|c|c|c|c|c|}
\hline & \multicolumn{2}{|c|}{$\begin{array}{l}\text { Life prolonging } \\
\text { treatment }\end{array}$} & \multicolumn{2}{|c|}{$\begin{array}{l}\text { Withholding } \\
\text { treatment }\end{array}$} & \multicolumn{2}{|c|}{$\begin{array}{l}\text { Withdrawing } \\
\text { treatment }\end{array}$} & \multicolumn{2}{|c|}{$\begin{array}{l}\text { Intensification of } \\
\text { alleviation of } \\
\text { symptoms }\end{array}$} & \multicolumn{2}{|c|}{$\begin{array}{l}\text { Administration of } \\
\text { a medication } \\
\text { to deliberately } \\
\text { hasten death }\end{array}$} & \multicolumn{2}{|c|}{ No decision } & \multirow{2}{*}{$\begin{array}{c}\begin{array}{c}\text { Total } \\
\text { deaths }\end{array} \\
\mathrm{n}\end{array}$} \\
\hline & $\mathrm{n}$ & $\%$ & $\mathrm{n}$ & $\%$ & $\mathrm{n}$ & $\%$ & $\mathrm{n}$ & $\%$ & $n$ & $\%$ & $n$ & $\%$ & \\
\hline \multicolumn{14}{|l|}{ Gender } \\
\hline Man & 302 & 15.62 & 335 & 17.32 & 105 & 5.43 & 641 & 33.15 & 20 & 1.02 & 531 & 27.46 & 1934 \\
\hline Woman & 274 & 13.74 & 354 & 17.78 & 94 & 4.72 & 686 & 34.45 & 18 & 0.89 & 566 & 28.42 & 1991 \\
\hline$p$ value & & 0.0865 & & 0.7323 & & 0.3214 & & 0.4289 & & 0.6790 & & 0.5478 & \\
\hline \multicolumn{14}{|l|}{ Age } \\
\hline $18-49$ & 37 & 24.82 & 14 & 9.41 & 7 & 4.71 & 50 & 33.62 & 1 & 0.56 & 40 & 26.89 & 149 \\
\hline $50-69$ & 139 & 19.79 & 74 & 10.52 & 43 & 6.11 & 268 & 38.08 & 11 & 1.63 & 168 & 23.87 & 704 \\
\hline $70-79$ & 113 & 14.63 & 128 & 16.63 & 42 & 5.46 & 294 & 38.20 & 7 & 0.90 & 186 & 24.17 & 770 \\
\hline 80-89 & 204 & 13.05 & 309 & 19.79 & 79 & 5.06 & 486 & 31.13 & 16 & 1.04 & 467 & 29.92 & 1561 \\
\hline $90+$ & 83 & 11.30 & 163 & 22.07 & 29 & 3.93 & 227 & 30.74 & 2 & 0.27 & 234 & 31.69 & 738 \\
\hline$p$ value & & $<0.0001$ & & $<0.0001$ & & 0.4066 & & 0.0003 & & 0.1118 & & 0.0008 & \\
\hline \multicolumn{14}{|l|}{ Place of death } \\
\hline At home & 104 & 15.60 & 100 & 14.96 & 22 & 3.29 & 150 & 22.44 & 9 & 1.37 & 283 & 42.34 & 668 \\
\hline Public hospital & 334 & 15.67 & 393 & 18.44 & 121 & 5.68 & 793 & 37.21 & 16 & 0.76 & 474 & 22.24 & 2131 \\
\hline Private hospital & 59 & 14.97 & 56 & 14.15 & 23 & 5.81 & 156 & 39.41 & 8 & 1.92 & 94 & 23.75 & 396 \\
\hline Hospice, retirement home & 66 & 9.95 & 132 & 19.83 & 33 & 4.96 & 207 & 31.10 & 3 & 0.51 & 224 & 33.65 & 666 \\
\hline Public place, street or other & 12 & 18.90 & 8 & 12.43 & 0 & 0.00 & 20 & 31.08 & 1 & 1.85 & 23 & 35.74 & 64 \\
\hline$p$ value & & 0.0037 & & 0.0124 & & 0.0181 & & $<0.0001$ & & 0.1017 & & $<0.0001$ & \\
\hline \multicolumn{14}{|l|}{ Cause of death } \\
\hline Cancer & 69 & 5.57 & 171 & 13.76 & 50 & 4.02 & 643 & 51.73 & 21 & 1.68 & 289 & 23.25 & 1243 \\
\hline Cardio-vascular disease & 208 & 24.92 & 129 & 15.46 & 42 & 5.03 & 175 & 20.97 & 4 & 0.44 & 277 & 33.19 & 835 \\
\hline Neurological disease & 68 & 11.02 & 146 & 23.59 & 42 & 6.79 & 183 & 29.57 & 5 & 0.76 & 175 & 28.27 & 619 \\
\hline Infectious disease & 63 & 21.01 & 64 & 21.43 & 15 & 5.02 & 101 & 33.81 & 3 & 0.99 & 53 & 17.74 & 299 \\
\hline Respiratory disease & 45 & 17.29 & 76 & 29.37 & 11 & 4.25 & 61 & 23.57 & 3 & 1.17 & 63 & 24.35 & 259 \\
\hline Digestive disease & 42 & 25.77 & 27 & 16.53 & 7 & 4.29 & 47 & 28.78 & 1 & 0.75 & 39 & 23.88 & 163 \\
\hline Mental or psychiatric disorder & 7 & 5.57 & 24 & 19.85 & 10 & 8.27 & 38 & 31.43 & 1 & 0.97 & 41 & 33.91 & 121 \\
\hline \multirow[t]{2}{*}{ Other cause } & 64 & 19.28 & 45 & 13.55 & 21 & 6.33 & 64 & 19.28 & 0 & 0.00 & 138 & 41.57 & 332 \\
\hline & 11 & 20.26 & 5 & 9.49 & 2 & 3.80 & 14 & 26.58 & 0 & 0.00 & 21 & 39.87 & 53 \\
\hline$p$ value & & $<0.0001$ & & $<0.0001$ & & 0.1918 & & $<0.0001$ & & $(0.0728)$ & & $<0.0001$ & \\
\hline \multicolumn{14}{|l|}{ Incurable disease } \\
\hline Yes & 235 & 9.63 & 434 & 17.79 & 120 & 4.92 & 982 & 40.25 & 29 & 1.17 & 640 & 26.23 & 2440 \\
\hline No & 303 & 23.09 & 224 & 17.06 & 72 & 5.48 & 319 & 24.29 & 9 & 0.68 & 386 & 29.39 & 1313 \\
\hline . & 38 & 21.92 & 31 & 17.78 & 7 & 4.05 & 26 & 14.82 & 0 & 0.00 & 72 & 41.43 & 173 \\
\hline$p$ value & & $<0.0001$ & & 0.5357 & & 0.5044 & & $<0.0001$ & & 0.2138 & & 0.0231 & \\
\hline
\end{tabular}

All percentages are weighted for non-response, to ensure there are representative of the initial. The percentage cannot be derived from the absolute unweighted absolute numbers. The $\mathrm{p}$ values are obtained with a Fisher exact test. Due to some cells with small numbers, some assumptions of a chi2 test are complied with. 
Table 3 Frequency of all the different medical end-of-life decisions in France by physicians' characteristics (non sudden deaths)

\begin{tabular}{|c|c|c|c|c|c|c|c|c|c|c|c|c|c|}
\hline & \multicolumn{2}{|c|}{$\begin{array}{l}\text { Life prolonging } \\
\text { treatment }\end{array}$} & \multicolumn{2}{|c|}{$\begin{array}{l}\text { Withholding } \\
\text { treatment }\end{array}$} & \multicolumn{2}{|c|}{$\begin{array}{l}\text { Withdrawing } \\
\text { treatment }\end{array}$} & \multicolumn{2}{|c|}{$\begin{array}{l}\text { Intensification } \\
\text { of alleviation } \\
\text { of symptoms }\end{array}$} & \multicolumn{2}{|c|}{$\begin{array}{c}\text { Administration } \\
\text { of a medication } \\
\text { to deliberately } \\
\text { hasten death } \\
\end{array}$} & \multicolumn{2}{|c|}{ No decision } & \multirow[t]{2}{*}{$\begin{array}{l}\text { Total } \\
\text { deaths }\end{array}$} \\
\hline & $\mathbf{n}$ & $\%$ & $\mathbf{n}$ & $\%$ & $\mathbf{n}$ & $\%$ & $\mathrm{n}$ & $\%$ & $n$ & $\%$ & $\mathrm{n}$ & $\%$ & \\
\hline \multicolumn{14}{|l|}{ Gender } \\
\hline Man & 414 & 15.9 & 452 & 17.4 & 123 & 4.7 & 822 & 31.6 & 29 & 1.1 & 758 & 29.2 & 2598 \\
\hline \multirow[t]{2}{*}{ Woman } & 156 & 12.1 & 232 & 18.0 & 74 & 5.8 & 485 & 37.7 & 8 & 0.6 & 332 & 25.8 & 1287 \\
\hline & 6 & 16.2 & 4 & 10.2 & 2 & 5.1 & 20 & 50.8 & 0 & 0.0 & 7 & 17.8 & 39 \\
\hline$P$ value & & 0.0074 & & 0.4357 & & 0.4072 & & $<0.0001$ & & 0.2600 & & 0.0453 & \\
\hline \multicolumn{14}{|l|}{ Age } \\
\hline Under 40 & 120 & 13.8 & 161 & 18.4 & 50 & 5.7 & 351 & 40.2 & 14 & 1.5 & 178 & 20.4 & 874 \\
\hline $40-49$ & 168 & 14.9 & 198 & 17.6 & 75 & 6.7 & 371 & 33.0 & 3 & 0.3 & 310 & 27.5 & 1125 \\
\hline $50-59$ & 200 & 14.7 & 237 & 17.5 & 56 & 4.1 & 424 & 31.3 & 14 & 1.0 & 424 & 31.3 & 1355 \\
\hline 60 and over & 86 & 15.8 & 87 & 16.0 & 16 & 2.9 & 169 & 31.1 & 7 & 1.2 & 179 & 33.0 & 543 \\
\hline . & 3 & 9.6 & 5 & 18.1 & 2 & 7.2 & 11 & 39.8 & 0 & 0.0 & 7 & 25.3 & 28 \\
\hline$P$ value & & 0.8056 & & 0.8511 & & 0.0049 & & 0.0002 & & 0.0600 & & $<0.0001$ & \\
\hline \multicolumn{14}{|l|}{ Speciality } \\
\hline General practice & 142 & 11.0 & 229 & 17.7 & 47 & 3.6 & 410 & 31.7 & 13 & 1.0 & 450 & 34.8 & 1292 \\
\hline Intensive care & 136 & 29.1 & 58 & 12.4 & 58 & 12.4 & 147 & 31.4 & 5 & 1.0 & 64 & 13.7 & 468 \\
\hline Oncology & 13 & 7.1 & 17 & 9.5 & 6 & 3.4 & 96 & 53.9 & 6 & 3.1 & 41 & 23.0 & 178 \\
\hline Cardiology & 32 & 26.7 & 26 & 21.6 & 1 & 0.8 & 34 & 28.2 & 5 & 4.4 & 22 & 18.3 & 120 \\
\hline Surgery & 16 & 24.1 & 7 & 10.8 & 2 & 3.1 & 22 & 34.1 & 0 & 0.0 & 18 & 27.9 & 65 \\
\hline Geriatrics & 75 & 8.8 & 151 & 17.7 & 44 & 5.2 & 330 & 38.7 & 3 & 0.3 & 250 & 29.3 & 853 \\
\hline Emergency & 81 & 24.4 & 63 & 18.9 & 15 & 4.5 & 50 & 15.0 & 0 & 0.0 & 124 & 37.2 & 333 \\
\hline Neurology & 2 & 4.9 & 9 & 24.6 & 1 & 2.5 & 16 & 43.5 & 0 & 0.0 & 9 & 24.5 & 37 \\
\hline Other & 78 & 13.9 & 125 & 22.2 & 25 & 4.4 & 213 & 37.9 & 6 & 1.0 & 115 & 20.5 & 562 \\
\hline . & 1 & 4.2 & 3 & 14.4 & 2 & 9.6 & 11 & 52.7 & 0 & 0.0 & 4 & 19.2 & 21 \\
\hline$P$ value & & $<0.0001$ & & 0.0014 & & $(<0.0001)$ & & $<0.0001$ & & 0.0003 & & $<0.0001$ & \\
\hline \multicolumn{14}{|l|}{ Work context } \\
\hline General practice & 93 & 12.2 & 135 & 17.7 & 21 & 2.8 & 201 & 26.4 & 10 & 1.3 & 301 & 39.5 & 761 \\
\hline Public hospital & 352 & 17.9 & 357 & 18.1 & 123 & 6.2 & 670 & 34.0 & 17 & 0.8 & 451 & 22.9 & 1970 \\
\hline Private hospital & 47 & 16.6 & 31 & 11.0 & 17 & 6.0 & 120 & 42.4 & 4 & 1.4 & 64 & 22.6 & 283 \\
\hline $\begin{array}{l}\text { Medico-social, rehab. or } \\
\text { LTC establishment }\end{array}$ & 16 & 6.9 & 51 & 21.7 & 7 & 3.0 & 99 & 42.1 & 0 & 0.0 & 62 & 26.4 & 235 \\
\hline Other & 20 & 9.2 & 30 & 13.6 & 11 & 5.0 & 78 & 35.4 & 2 & 1.0 & 79 & 35.8 & 221 \\
\hline Several work contexts & 44 & 10.6 & 77 & 18.7 & 19 & 4.6 & 138 & 33.5 & 4 & 1.1 & 130 & 31.5 & 412 \\
\hline . & 4 & 9.1 & 6 & 14.3 & 1 & 2.4 & 21 & 50.2 & 0 & 0.0 & 10 & 23.9 & 42 \\
\hline$P$ value & & $<0.0001$ & & 0.0271 & & 0.0544 & & $<0.0001$ & & $(0.5054)$ & & $<0.0001$ & \\
\hline \multicolumn{14}{|l|}{ Size of agglomeration } \\
\hline$<5000$ & 55 & 8.5 & 118 & 18.4 & 25 & 3.9 & 212 & 33.0 & 10 & 1.6 & 222 & 34.6 & 642 \\
\hline $5-10000$ & 60 & 13.8 & 74 & 17.1 & 16 & 3.7 & 130 & 30.0 & 3 & 0.8 & 150 & 34.7 & 433 \\
\hline $20-20000$ & 72 & 15.2 & 84 & 17.8 & 20 & 4.2 & 153 & 32.4 & 5 & 1.1 & 138 & 29.2 & 472 \\
\hline $20-100000$ & 212 & 17.7 & 210 & 17.5 & 64 & 5.3 & 406 & 33.9 & 9 & 0.8 & 296 & 24.7 & 1197 \\
\hline $100-200000$ & 56 & 14.1 & 75 & 18.7 & 29 & 7.2 & 130 & 32.4 & 2 & 0.5 & 109 & 27.1 & 402 \\
\hline
\end{tabular}


Table 3 Frequency of all the different medical end-of-life decisions in France by physicians' characteristics (non sudden deaths) (Continued)

\begin{tabular}{|c|c|c|c|c|c|c|c|c|c|c|c|c|c|}
\hline$>200000$ & 107 & 16.0 & 110 & 16.4 & 41 & 6.1 & 256 & 38.2 & 6 & 0.9 & 150 & 22.4 & 670 \\
\hline . & 15 & 13.7 & 18 & 16.5 & 4 & 3.7 & 40 & 36.6 & 1 & 1.2 & 31 & 28.4 & 109 \\
\hline$P$ value & & $<0.0001$ & & 0.9308 & & 0.0891 & & 0.1108 & & $(0.6023)$ & & $<0.0001$ & \\
\hline \multicolumn{14}{|c|}{ Number of deaths certified in the past 3 months } \\
\hline 0 & 34 & 16.8 & 40 & 19.5 & 10 & 4.9 & 57 & 27.8 & 2 & 1.1 & 61 & 29.8 & 205 \\
\hline $1-2$ & 123 & 15.0 & 144 & 17.6 & 24 & 2.9 & 241 & 29.4 & 10 & 1.2 & 277 & 33.8 & 819 \\
\hline $3-4$ & 169 & 16.0 & 199 & 18.8 & 62 & 5.9 & 337 & 31.9 & 9 & 0.9 & 280 & 26.5 & 1056 \\
\hline $5-9$ & 149 & 15.2 & 156 & 15.8 & 50 & 5.1 & 354 & 35.9 & 8 & 0.8 & 269 & 27.3 & 986 \\
\hline $10-19$ & 60 & 11.6 & 100 & 19.3 & 34 & 6.6 & 202 & 39.1 & 5 & 1.0 & 116 & 22.4 & 517 \\
\hline \multirow[t]{2}{*}{$20+$} & 18 & 8.5 & 28 & 13.2 & 15 & 7.1 & 94 & 44.3 & 0 & 0.0 & 57 & 26.9 & 212 \\
\hline & 22 & 17.5 & 21 & 16.5 & 5 & 3.9 & 39 & 30.6 & 3 & 2.4 & 37 & 29.1 & 127 \\
\hline$P$ value & & 0.0534 & & 0.2641 & & 0.0259 & & $<0.0001$ & & $(0.4672)$ & & 0.0006 & \\
\hline \multicolumn{14}{|c|}{ In-service training on end-of-life } \\
\hline Yes & 197 & 10.6 & 311 & 16.7 & 101 & 5.4 & 712 & 38.3 & 10 & 0.6 & 526 & 28.3 & 1858 \\
\hline No & 370 & 18.7 & 364 & 18.3 & 94 & 4.7 & 588 & 29.6 & 25 & 1.2 & 543 & 27.4 & 1984 \\
\hline . & 8 & 10.0 & 13 & 15.5 & 5 & 5.9 & 26 & 30.9 & 3 & 3.1 & 29 & 34.5 & 84 \\
\hline
\end{tabular}

All percentages are weighted for non-response, to ensure there are representative of the initial. The percentage cannot be derived from the absolute unweighted absolute numbers. The $\mathrm{p}$ values are obtained with a Fisher exact test. Due to some cells with small numbers, some assumptions of a chi2 test are complied with.

in $14 \%$ of cases. These figures varied according to the type of decision: discussions with colleagues, family, or trusted third party were more frequent when decisions were more likely to hasten death (Table 4).

When a drug was administered to deliberately hasten death on the patient's explicit request, this request was repeated 8 times out of 11 , and an explicit request for euthanasia was made in 6 cases. When the sole decision was to prolong life, it was at patient's explicit request in $4 \%$ of the cases.

Among the 55 explicit requests for euthanasia reported by the physicians, 6 were granted, whereas in 44 cases the physician chose to intensify the alleviation of symptoms, and in 1 case no decision was reported, except for doing everything possible to prolong the life.

For almost half of the physicians, "deep sedation for distress in terminal phase" was the term that best described the decision to deliberately administer a medication to hasten death; much less frequently "symptom treatment" or "non-treatment decision". Only 5 physicians reported "euthanasia".

\section{Discussion and conclusions}

\section{Main findings}

For the first time, this study provides data on end-oflife medical decisions on a representative sample of all deaths in France.

In $12.2 \%$ of cases, the decision was to do everything possible to prolong life. Non-treatment decisions were made in $16.8 \%$ of cases, treatment was withheld in $14.6 \%$ and withdrawn in $4.2 \%$. Alleviation of symptoms with opioids and/or benzodiazepines was intensified in $28.1 \%$ of cases, A drug was administered to deliberately hasten death in $0.8 \%$ of cases, at the patient's request in 11 out of the 38 cases concerned.

The study shows that end-of-life medical decisions that may hasten death are relatively frequent in France. Most of such decisions are in compliance with the law, which allows physicians to withhold or withdraw life prolonging treatment and to intensify alleviation of symptoms even if unintended side effects may hasten death ("double effect"), as long as the first intention is not to hasten death. In a much smaller number of cases (3.1\%), the death followed a decision made with the declared intention of hastening death. The patient's pathology is the main factor governing this type of decision. Even though most end-of-life medical decisions are made in compliance with the 2005 law, and decisions leading to a strong likelihood of death are more frequently taken after discussion with the patient or trusted third party and the medical staff (other doctors, nursing staff), the study shows that the legal provisions governing these decisions are not always fully respected.

\section{Strengths and limitations}

For the first time in France, this study provides data on end-of-life decisions on a representative sample of deaths, whatever the cause, wherever the death took place. It gives objective results on this important issue that will inform and assist both public and legislative debate. The French national end-of-life watchdog Observatoire National de la Fin de Vie (ONFV) has noted the 
Table 4 Characteristics of decision-making by type of medical decision (non sudden deaths)

\begin{tabular}{|c|c|c|c|c|c|c|c|c|c|c|}
\hline & \multicolumn{2}{|c|}{$\begin{array}{l}\text { Life prolonging } \\
\text { treatment }\end{array}$} & \multicolumn{2}{|c|}{$\begin{array}{l}\text { Withholding } \\
\text { treatment }\end{array}$} & \multicolumn{2}{|c|}{$\begin{array}{l}\text { Withdrawing } \\
\text { treatment }\end{array}$} & \multicolumn{2}{|c|}{$\begin{array}{l}\text { Intensification } \\
\text { of alleviation } \\
\text { of symptoms }\end{array}$} & \multicolumn{2}{|c|}{$\begin{array}{l}\text { Administration } \\
\text { of a medication } \\
\text { to deliberately } \\
\text { hasten death }\end{array}$} \\
\hline & $\mathrm{n}$ & $\%$ & n & $\%$ & $\mathbf{n}$ & $\%$ & $\mathbf{n}$ & $\%$ & $\mathrm{n}$ & $\%$ \\
\hline \multicolumn{11}{|c|}{ Decision discussed with patient (by respondent or other physician) } \\
\hline Yes & 55 & 9.6 & 40 & 8.02 & 12 & 8.63 & 263 & 19.82 & 6 & 16.18 \\
\hline No & 79 & 13.7 & 40 & 8.02 & 3 & 2.16 & 44 & 3.32 & 2 & 6.31 \\
\hline Patient not competent & 308 & 53.6 & 357 & 71.54 & 112 & 80.55 & 904 & 68.12 & 25 & 67.40 \\
\hline Don't know & 19 & 3.3 & 6 & 1.20 & 3 & 2.19 & 26 & 1.96 & 1 & 3.46 \\
\hline No response & 114 & 19.8 & 56 & 11.22 & 9 & 6.47 & 90 & 6.78 & 2 & 6.65 \\
\hline Discussion, per 100 competent patients & & 41.0 & & 50.0 & & 80.0 & & 85.7 & & 71.9 \\
\hline \multicolumn{11}{|l|}{ Decision following patient's explicit request } \\
\hline Yes and request repeated & 14 & 2.43 & 20 & 4.03 & 9 & 6.39 & 166 & 12.50 & 8 & 21.00 \\
\hline Yes and request not repeated & 4 & 0.69 & 5 & 1.01 & 1 & 0.62 & 41 & 3.09 & 2 & 5.85 \\
\hline Yes and do not know whether request repeated & 7 & 1.22 & 7 & 1.41 & 0 & 0.00 & 40 & 3.01 & 1 & 2.63 \\
\hline No & 418 & 72.57 & 392 & 79.03 & 117 & 83.06 & 962 & 72.44 & 22 & 58.92 \\
\hline No response & 133 & 23.09 & 72 & 14.52 & 14 & 9.94 & 119 & 8.96 & 4 & 11.60 \\
\hline \multicolumn{11}{|c|}{ Patient expressed wish at some moment to hasten death } \\
\hline Yes & 13 & 2.26 & 46 & 9.26 & 14 & 10.00 & 203 & 15.31 & 14 & 38.35 \\
\hline No & 333 & 57.81 & 261 & 52.52 & 86 & 61.43 & 809 & 61.01 & 11 & 28.99 \\
\hline Do not know & 115 & 19.97 & 126 & 25.35 & 30 & 21.43 & 210 & 15.84 & 10 & 27.30 \\
\hline No response & 115 & 19.97 & 64 & 12.88 & 10 & 7.14 & 104 & 7.84 & 2 & 5.36 \\
\hline
\end{tabular}

\section{Decision discussed with another person}

incompetent person

\begin{tabular}{|c|c|c|c|c|c|c|c|c|c|}
\hline Doctors & 102 & 33.12 & 136 & 38.10 & 62 & 55.36 & 434 & 48.01 & 14 \\
\hline Nurses and nursing assistants, medical care team & 49 & 15.91 & 95 & 26.61 & 42 & 37.50 & 326 & 36.06 & 10 \\
\hline Family & 74 & 24.03 & 171 & 47.90 & 64 & 57.14 & 549 & 60.73 & 19 \\
\hline Other people & 1 & 0.32 & 3 & 0.84 & 0 & 0.00 & 4 & 0.44 & 0 \\
\hline Trusted third party & 19 & 6.17 & 29 & 8.12 & 15 & 13.39 & 150 & 16.59 & 5 \\
\hline As part of a collective decision & 16 & 5.19 & 24 & 6.72 & 15 & 13.39 & 137 & 15.15 & 5 \\
\hline No & 119 & 38.64 & 48 & 13.45 & 4 & 3.57 & 57 & 6.31 & 1 \\
\hline No response & 7 & 2.27 & 8 & 2.24 & 1 & 0.89 & 11 & 1.22 & 0 \\
\hline
\end{tabular}

\section{Trusted third party}

\section{incompetent person}

$\begin{array}{lcccccccccc}\text { Yes and involved in discussion phase } & 57 & 18.51 & 71 & 19.89 & 22 & 19.64 & 312 & 34.55 & 8 & 32.00 \\ \text { Yes and not involved in discussion phase } & 19 & 6.17 & 7 & 1.96 & 6 & 5.36 & 11 & 1.22 & 1 & 4.00 \\ \text { Yes and do not know whether involved or not } & 4 & 1.30 & 2 & 0.56 & 1 & 0.89 & 3 & 0.33 & 0 & 0.00 \\ \text { No } & 99 & 32.14 & 108 & 30.25 & 31 & 27.68 & 295 & 32.67 & 10 & 40.00 \\ \text { No because patient not capable of naming one } & 54 & 17.53 & 105 & 29.41 & 27 & 24.11 & 177 & 19.60 & 4 & 16.00 \\ \text { Do not know } & 75 & 24.35 & 64 & 17.93 & 25 & 22.32 & 105 & 11.63 & 2 & 8.00\end{array}$

\section{Advance directive}

\section{incompetent person}

\begin{tabular}{|c|c|c|c|c|c|c|c|c|c|}
\hline Yes and was an important factor in the decision & 1 & 0.32 & 2 & 0.56 & 0 & 0.00 & 9 & 1.00 & 2 \\
\hline Yes and was not important factor in the decision & 0 & 0.00 & 2 & 0.56 & 0 & 0.00 & 3 & 0.33 & 0 \\
\hline Yes and do not know whether important factor & 0 & 0.00 & 0 & 0.00 & 0 & 0.00 & 0 & 0.00 & 0 \\
\hline
\end{tabular}


Table 4 Characteristics of decision-making by type of medical decision (non sudden deaths) (Continued)

\begin{tabular}{lcccccccccc}
\hline No & 185 & 60.06 & 233 & 65.45 & 75 & 66.96 & 685 & 75.86 & 16 & 64.00 \\
Do not know & 122 & 39.61 & 119 & 33.43 & 37 & 33.04 & 206 & 22.81 & 7 & 28.00 \\
\hline $\begin{array}{l}\text { Best description of the medical act } \\
\quad \text { Symptom treatment }\end{array}$ & 337 & 58.41 & 144 & 28.92 & 17 & 12.15 & 717 & 54.03 & 7 & 19.44 \\
$\quad$ Decision to withhold or withdraw treatment & 20 & 3.47 & 237 & 47.59 & 104 & 74.31 & 123 & 9.27 & 6 & 17.06 \\
Sedation for distress in terminal phase & 10 & 1.73 & 19 & 3.82 & 1 & 0.60 & 361 & 27.21 & 17 & 45.59 \\
Euthanasia & 0 & 0.00 & 0 & 0.00 & 1 & 0.79 & 1 & 0.07 & 5 & 12.04 \\
Medically assisted suicide & 0 & 0.00 & 0 & 0.00 & 0 & 0.00 & 0 & 0.00 & 0 & 0.00 \\
Other & 66 & 11.44 & 30 & 6.02 & 6 & 4.29 & 18 & 1.36 & 0 & 0.00 \\
No response & 144 & 24.96 & 68 & 13.65 & 11 & 7.86 & 107 & 8.06 & 2 & 5.87 \\
\hline
\end{tabular}

All percentages are weighted for non-response, to ensure there are representative of the initial. The percentage cannot be derived from the absolute unweighted absolute numbers.

lack of available scientific data on medical practices in this regard in France [13].

This survey also shows that investigating this sensitive topic and even exploring illegal practices is possible in France; this was by no means certain when the study was first launched. That is why we deliberately adapted the questionnaire to take account of the French legislative context and of the French sensitivity on this issue revealed in preliminary tests, even at the expense of comparability with other countries.

From a methodological viewpoint, we conducted the survey using a mixed mode approach, i.e. enabling physicians to answer either by Internet or by returning the questionnaire in a paid-reply envelope. We developed a different process for each of the response channels in order to guarantee total anonymity.

The $40 \%$ participation rate is towards the bottom of the range of the European EURELD surveys and could be considered as a limitation [4]. One explanation for this low rate might be that, unlike some of the EURELD surveys with a higher response rate, we did not stratify the sample according to the likelihood that death followed a potential end-oflife decision, and therefore sent our questionnaire to proportionally more physicians who would probably consider their patient's end of life to be irrelevant to the survey. But in fact, this participation rate is fairly close to that for other surveys of French physicians $[7,14]$. In the non-response survey, the main reasons given were lack of time and refusal to take part in any kind of survey. Few doctors mentioned the survey topic as a reason for not responding. The length of the questionnaire and, above all, the need to look through the patient's case history may have been dissuasive. Some doctors did not feel the survey concerned them, especially if they had not been treating the patient prior to death, as the under-representation of deaths from external causes also suggests.

Nevertheless, the comparison of respondent and nonrespondent physicians' profiles reveals no significant differences, lending support to our belief that this assessment of end-of-life medical decisions is likely to be reliable, although an under-estimation of illegal practices cannot be excluded.

This survey, like others on the same topic, [2,4,15-27] is based on the responses of physicians, who are best placed to answer questions about decisions for which they have taken responsibility. However, one limitation is that they can only report on their own experience of a reality that also involves other people (the patient, the family or friends, other medical staff etc.) who might have different points of view.

\section{Comparison with end-of-life decisions in other studies}

The only figures available in France about end-of-life decisions concerned withholding or withdrawal of life support were conducted in 2004, prior to the law. In the MAHO survey [28], carried out in public hospitals, withholding or withdrawing life support was less frequent than in our results concerning all public hospitals $(45.4 \%$ of the deceased patients included in the study, vs. $51.2 \%$ in our survey). In the DALISA survey $[8,14]$, carried out in emergency departments, withholding life support was observed in $41.5 \%$ of the deaths, and withdrawing (alone or preceded by withholding) life support in $58.5 \%$, vs. $89 \%$ and $11 \%$ respectively, in our results concerning emergency departments. These differences may be partially explained by the different study designs; the legislation has also changed between these studies and ours.

It is not easy to compare study findings with those conducted elsewhere, even where similar survey protocols are used (retrospective survey of certifying physicians, with a representative sample of deaths). The definition we used for sudden deaths and the wording and approach for questions about end-of-life medical decisions were different to those used in EURELD type studies. In particular, we chose a two-step approach: a question on a treatment/decision (withholding, withdrawing a treatment, intensifying the 
alleviation of pain); and, for each decision made, its possible or certain effect on hastening death as well as the intention of hastening death, is investigated. According to Seale [29] who compared the two wordings for UK, the two-step approach gives a lower percentage of end-of-life decisions compared to the approach where the potential effect of hastening death is included in the question of treatment. As a result, end-of-life decisions could not be classified in an identical manner as Eureld, although we tried to get as close as possible. If we had replaced our definition of "sudden death" (deaths declared by physician as "sudden and unexpected" and for which they cannot provide any information about the patient's end of life) with the EURELD definition, the percentage of sudden deaths would have more than doubled (from 16.9 to 39.3\%). This change of definition of sudden deaths reduces more the proportion of medical decisions without any intention regarding deaths than the one that possibly or certainly hastened deaths.

Compared with the 2001 Eureld survey results [4] and more recent results in Belgium [30] and the Netherlands [31], and taking the definitions of medical decisions closest to those used in these surveys, the proportion of sudden deaths in the French data (39\%) is higher than that of all other countries (29-34\%). The percentage of deaths for which a decision was made that possibly or certainly hastened death (40\%), is around the average observed in the other European countries. It is much higher than in Italy, (29\% in 2001), but well below the levels in Switzerland, where assisted suicide is legal (51\% in 2001), and in the Netherlands (57\% in 2010) and Belgium (48\% in 2007), two countries where euthanasia has been legalised. In France, intensification of treatment to alleviate pain and/ or symptoms is close to the level observed in Belgium in 2007, but slightly higher than in most EURELD countries. However, levels of withholding or withdrawal of treatment are similar to those observed in more recent surveys in Belgium and the Netherlands.

France ranks among the countries with a low percentage of physician-assisted dying by administration of a drug to deliberately hasten death. At less than 1\%, this level is close to the Danish level in 2001, it is higher than in Sweden and Italy and much lower than in the Netherlands and Belgium. No physician-assisted suicide was reported and euthanasia (at the patient's request) is very rare. According to our results, a fifth of medical decisions that possibly or certainly hastened deaths are made at the patient's request, (a third for deaths with a decision to administer a medication to deliberately hasten death). This is much lower than in the Netherlands and Belgium (where Euthanasia is legal). It is higher than in other European countries in the 2001 Eureld survey. Discussion of the decision with competent patients was more frequent in France (80\%) than in most European countries in 2001 with the exception of the Netherlands. Also for non-competent patients, the family is very often involved in the discussion (78\%), less frequently than in the Netherlands, similarly to Belgium-Switzerland but much more frequently than in other countries. This might reflect an effect of the French law on discussion with patients or relatives.

Overall, the main results on end-of-life medical decisions are consistent with those of surveys conducted in other countries: intensification of pain relief treatment is the most common decision [17] and administration of drugs to intentionally end the patient's life is rare.

\section{Discussion of the findings in light of the French law}

In France, the 2005 law on patients' rights and the end of life defined a legal framework allowing patients to refuse any treatment they consider unreasonable, and allowing doctors to decide on treatments that may have the side effect of hastening death, in accordance with the wishes expressed by the patient [1]. The medical decisions observed in our survey mostly complied with French legal requirements, as the 2005 Act allows withholding and withdrawal of life support, and intensified alleviation of symptoms even when it may (unintentionally) hasten death. Indeed $80 \%$ of the physicians who made this decision said they were aware of its potential "double effect". Some decisions overstepped the law, although very rarely. A drug was administered with the explicit intention of hastening death - an act that can be considered as poisoning under French law - at the patient's explicit request in $0.2 \%$ of these deaths, and without a clear patient request in another $0.6 \%$. Intention to hasten death was also declared, even if very infrequently, in some of the decisions of life support withholding or withdrawal or of intensified alleviation of symptoms. As a whole, decisions with intention to hasten death amounted to $3.1 \%$ of all deaths, and only one out five of these decisions was made on the patient's explicit request, whereas such a request is mandatory in all countries where the law permits euthanasia in specific cases, and is part of the ONFV definition of euthanasia [1].

The decision making processes observed in our survey were far from complying with the 2005 legal procedures, which are required whatever the end-of-life decision made. A discussion with the patient when competent was mentioned by the physician in only $72 \%$ of the cases when a drug was administered intentionally to hasten death, in $80 \%$ when life support was withdrawn, and $41 \%$ when everything was done to prolong life.

When an end-of-life decision is made for an incompetent patient, advance directives if any, discussion with a trusted third party previously named by the patient, if any, discussion with the family, if any, discussion with a colleague not in charge of the patient, with colleagues and with nursing staff members, are compulsory 
components of the decision-making process. When a treatment was withdrawn for a possibly incompetent patient, the decision was discussed with other doctors in $39 \%$ of cases, with the nursing staff in $27 \%$ of cases and with the family in $50 \%$ of cases. The physician made this decision alone in $14 \%$ of cases. When a drug was administered with the intention of hastening death, the decision was discussed in 14, 10, 19 and 4 cases out of 24 , respectively.

Looking at these discrepancies between legal requirements and actual practice, we should not forget that our survey concerned deaths that occurred in December 2009 , less than three years after the revision of the medical ethics charter. There is still a lot to be done through medical education and population awareness-raising to ensure that no physician is obliged to face such difficult decisions alone.

\section{Conclusion}

In conclusion, these results provide an overview of end-oflife medical decisions in France, three years after the 2005 regulations were enacted, and for the first time on a large sample representative of all kinds of deaths. They are objective results in the context of the current legislation. They will help medical authorities and policy makers to examine how the act of parliament is applied and to understand more clearly which features of the current law are difficult to comply with. They will inform and assist the current public debate on this important topic. They will also serve as a baseline to investigate future changes.

\section{Additional files}

Additional file 1: Key questions on medical decisions of end-of-life in the French survey.

Additional file 2: Questionnaire of the French survey on End-of-life.

\section{Competing interests}

The authors declare that they have no competing interest.

\section{Authors' contributions}

SP participated in the conception and design of the survey and study, supervised the data collection, coordinated the study, performed the statistical analyses and drafted the manuscript. AM participated in the conception and design of the survey and study, supervised the data collection, performed the statistical analysis and draft the manuscript. SP and RA participated in the conception and design of the survey and study, critically revised the manuscript for important content. All authors read and approved the final manuscript.

\section{Acknowledgements}

This survey could not have been done without the financial support of the Institut National d'Etudes Démographiques and the Health Ministry's Direction Générale de la Santé (represented by A. Fontaine and E. Gaillard).

We would like to thank:

- The survey's steering committee for their support and constructive discussions throughout the design and first analysis of the survey (Piernick Cressard and Francois Stefani of the Conseil National de l'Ordre des Médecins National medical council -, Eric Jougla, Albertine Aouba, Grégoire Rey of
CepiDc at Institut national de la Santé et de la Recherche médicale - French national Institute of health and medical research-);

- Chantal Cases, Director of Ined for her constant support throughout the survey and her advice on data analysis;

- Our "trusted third party" partners Jeanne Fresson of the Department of Medical Information at the Maternité Universitaire de Nancy and Epiconcept for the Internet response channel;

- INED's surveys department, which was the pillar for data collection, and Amandine Stephan for her contribution in coordinating the survey;

- INED's administration; IT department and statistical methods department for their involvement in different aspects of this project;

- Johan Bilsen and Joachim Cohen from the End-of-life Care research group at the Vrije universiteit Brussel for their advice on the design of the survey;

- Françoise Riou for her comments on the manuscript

- All those who have been involved in the different steps of this survey (questionnaire testing, pilot survey, data capture...)

And of course, all our thanks and gratitude to all the physicians who gave their time to take part in the survey.

\section{Author details}

${ }^{1}$ Institut National d'Etudes Démographiques, 133, boulevard Davout, 75980 Paris cedex 20, France. ${ }^{2}$ Australian Demographic and Social Research Institute, Australian National University, Canberra, Australia. ${ }^{3}$ Robert Debré Hospital, Assistance Publique-Hôpitaux de Paris, Paris, France. ${ }^{4}$ Observatoire National de la Fin de Vie, Paris, France. ${ }^{5}$ Jean Minjoz Hospital, Besançon, France.

Received: 5 April 2012 Accepted: 23 November 2012

Published: 3 December 2012

\section{References}

1. Loi $n^{\circ} 2005-370$ du 22 avril 2005 relative aux droits des malades et à la fin de vie. In Journal officiel de la République française. 23 rd April. Paris; 2005:7089.

2. Deliens L, Mortier F, Bilsen J, Cosyns M, Stichele vander R, Vanoverloop J, Ingels $K$ : End-of-life decisions in medical practice in Flanders, Belgium: a nationwide survey. Lancet 2000, 356(9244):1806-1811.

3. Van Delden JM, Löfmark R, Deliens L, Bosshard G, Norup M, Cecioni R, Van der Heide A, EURELD Consortium: Do-not-resuscitate decisions in six European countries. Crit Care Med 2006, 34(6):1689-1690.

4. Van der Heide A, Deliens L, Faisst K, Nilstun T, Norup M, Paci E, Van der Wal G, Van der Maas PJ: End-of-life decision-making in six european countries: descriptive study. Lancet 2003, 362(9381):345-350.

5. Giannini A: End-of-life practices in european intensive care units. JAMA 2003, 290(22):2939.

6. Ferrand $E$, Marty J: Prehospital withholding and withdrawal of life-sustaining treatments. The French LATASAMU survey. Intensive Care Med 2006, 32(10):1149-1154.

7. Ferrand $E$, Robert R, Ingrand P, Lemaire F: Withholding and withdrawal of life support in intensive-care units in France: a prospective survey. Lancet 2001, 357:9-14.

8. Le Conte P, Riochet D, Batard E, Volteau C, Giraudeau B, Arnaudet I, Labastire L, Levraut J, Thys F, Lauque D, et al: Death in emergency departments: a multicenter cross-sectional survey with analysis of withholding and withdrawing life support. Intensive Care Med 2010, 36:765-772.

9. Ferrand E, Dreyfus J-F, Chastrusse M, Ellien F, Lemaire F, Fischler M: Evolution of requests to hasten death among patients managed by palliative care teams in France: A multicentre cross-sectional survey (DemandE). Eur J Cancer 2012, 48(3):368-376.

10. Chambaere K, Bilsen J, Cohen J, Pousset G, Onwuteaka-Philipsen DB, Mortier F, Deliens L: A post-mortem survey on end-of-life decisions using a representative sample of death certificates in Flanders, Belgium: research protocol. BMC Publ Health 2008, 8(299):1-10.

11. Brouard N, Aubry R, Monnier A, Pennec S, Pontone S: Questionnaire auto-administré via I'Internet avec préservation de l'anonymat absolument nécessaire dans une enquête sur la " Fin de vie ». In Sixième Colloque francophone sur les Sondages. Tanger, Maroc: 2010

[Self-administered questionnaire by Internet with preservation of anonymity absolutely necessary in a investigation of end-of life survey. $6^{\text {th }}$ conference of French speaking association of surveys scientists]. 
12. American Association for Public Opinion Research (Ed): Outcome rate calculator V3.1. 2010. www.aapor.org/researchers/ ResponseRateCalculatorVer3.1_1_22_22_10.xls.

13. Observatoire national de la fin de vie: Fin de vie: un premier état des lieux - rapport 2011. 2012:268. Paris https://sites.google.com/site/ observatoirenationalfindevie/publications/rapport-annuel.

14. Le Conte P, Batard E, Pinaud V, Evain Y, Potel G: Décisions de limitation ou d'arrêt des thérapeutiques actives dans les services d'urgence (wilthholding and withdrawing decisions in the emergency department). Reanimation 2008, 17(8):802-806.

15. Bilsen J: End-of-life decisions in medical practice in Flanders, Belgium Beslissingen rond het levenseinde in de medische praktijk in Vlaanderen, België. Brussel: Vrije Universiteit; 2005.

16. Bilsen J, Vander Stichele R, Broeckaert B, Mortier F, Deliens L: Changes in medical end-of-life practices during the legalization process of euthanasia in Belgium. Soc Sci Med 2007, 65(4):803-808.

17. Van den Block L, Deschepper R, Bilsen J, Bossuyt N, Van Casteren V, Deliens L: Euthanasia and other end-of-life decisions: a mortality follow-back study in Belgium. BMC Publ Health 2009, 9:79.

18. Cohen J, Van Delden JM, Mortier F, Löfmark R, Norup M, Cartwright C, Faisst K, Canova C, Onwuteaka-Philipsen BD, Bilsen J: Influence of physicians' life stances on attitudes to end-of-life decisions and actual end-of-life decision-making in six countries. J Med Ethics 2008, 34(4):247-253.

19. Emanuel EJ, Fairclough DL, Daniels ER, Clarridge BR: Euthanasia and physician-assisted-suicide: attitudes and experiences of oncology patients, oncologists and the public. Lancet 1996, 347:1805-1810.

20. Hinkka H, Kosumen E, Lammi EK, Metsanoja R, Puustelli A, Kellokumpu-Lehtinen P: Decision making in terminal care: a survey of Finnish doctors' treatment decisions in end-of-life scenarios involving a terminal cancer and a terminal dementia patient. Palliat Med 2002, 16:195-204.

21. Kompanje EJO: End-of-life practices in european intensive care units. JAMA 2003, 290(22):2938-2939.

22. Kuhse $H$, Singer $P$, Baume $P$, Clark M, Rickard M: End-of-life dedcisions in Australian medical practice. Med J Aust 1997, 166:191-196.

23. Van der Maas PJ, Van Delden JM, Pijnenborg L, Looman CWN: Euthanasia and other medical decisions concerning the end of life. Lancet 1991 338(8768):669-674.

24. Van der Maas PJ, Van der Wal G, Haverkate I, De Graaff CLM, Kester JGC, Onwuteaka-Philipsen BD, Van der Heide A, Bosma JM, Willems DL: Euthanasia, physician-assisted suicide, and other medical practices involving the end of life in the Netherlands, 1990-1995. N Engl J Med 1996, 335(22):1699-1705.

25. Maessen M, Veldink JH, Onwuteaka-Philipsen DB, Vries De JM, Wokke JHJ Van der Wal G, Van der Berg LH: Trends and determinants of end-of-life practices in ALS in the Netherlands. Neurology 2009, 73(12):954-961.

26. Onwuteaka-Philipsen DB, Heide van der A, Koper D, Keij-Deerenberg I, Rietjens ACJ, Rupurt LM, Vrakking MA, Georges JJ, Muller TM, Wal van der G, et al: Euthanasia and other end-of-life decisions in the Netherlands in 1990, 1995, and 2001. Lancet 2003, 362(9381):395-399.

27. Bilsen J, Cohen J, Chambaere K, Pousset G, Onwuteaka-Philipsen BD, Mortier F, Deliens L: Medical End-of-Life practices under the Euthanasia law in Belgium. N Engl J Med 2009, 361(11):11189-11120.

28. Ferrand $E$, Jabre $P$, Vincent-Genod C, Aubry R, Badet M, Badia P, Cariou A Ellien F, Gounant V, Gil R, et al: Circumstances of death in hospitalized patients and nurses' perceptions. Arch Intern Med 2008, 168(8):867-875.

29. Seale C: End-of-life decisions in the UK involving medical practitioners. Palliat Med 2009, 23(3):198-204

30. Bilsen J, Cohen J, Chambaere K, Pousset G, Onwuteaka-Philipsen DB, Mortier F, Deliens L: Medical End-Of-Life Practices under the Euthanasia law in Belgium. N Engl J Med 2009, 361(11):1119-1121.

31. Onwuteaka-Philipsen BD, Brinkman-Stoppelenburg A, Penning C, de Jong-Krul GJF, van Delden JJM, van der Heide A: Trends in end-of-life practices before and after the enactment of the euthanasia law in the Netherlands from 1990 to 2010: a repeated cross-sectional survey. Lancet 2012, 380(9845):908-915.

doi:10.1186/1472-684X-11-25

Cite this article as: Pennec et al:: End-of-life medical decisions in France: a death certificate follow-up survey 5 years after the 2005 act of parliament on patients' rights and end of life. BMC Palliative Care 2012 $11: 25$.

\section{Submit your next manuscript to BioMed Central and take full advantage of:}

- Convenient online submission

- Thorough peer review

- No space constraints or color figure charges

- Immediate publication on acceptance

- Inclusion in PubMed, CAS, Scopus and Google Scholar

- Research which is freely available for redistribution 